\title{
Urodynamic Findings in Children with Cerebral Palsy Before Dorsal Rhizotomy Surgery
}

\author{
(1) Yılören Tanıdır1', (1) Mahir Bülent Özgen2, (1) Memet Özek33, (1) Tufan Tarcan1 \\ ${ }^{1}$ Marmara University Faculty of Medicine, Department of Urology, İstanbul, Turkiye \\ ${ }^{2}$ Acıbadem Healthcare Group, Clinic of Urology, Istanbul, Turkiye \\ ${ }^{3}$ Acıbadem Mehmet Ali Aydınlar University Faculty of Medicine, Department of Neurosurgery, Istanbul, Turkiye
}

\section{What's known on the subject? and What does the study add?}

It is well known that patients with upper motor neuron lesions may present with different urodynamic findings. To date, the number of published articles about urodynamic studies in patients with cerebral palsy is limited and of them, only half of them are about children. These present an important cross-section for assessing the need for urological follow-up which is not recommended by some authors. Our recent study provides an overview of those children, in terms of neurourological findings and symptoms.

\begin{abstract}
Objective: This study aims to investigate the neurourological and urodynamic findings of children with cerebral palsy (CP) that referred for dorsal rhizotomy surgery (DRS).

Materials and Methods: All children with CP who were scheduled for selective DRS were assessed with a detailed medical history, physical exam, urinalysis and urodynamic studies to assess bladder function and urinary problems. Urodynamic studies included filling and voiding cystometry, detrusor leak point pressure, external anal sphincter electromyography, flow rate and residual urine volume. All investigations and definitions relied on the standardisation of the International Continence Society.

Results: Overall, 24 boys and 10 girls were evaluated. The mean age of boys, and girls and the study group was 6.6 (1.7-9.8), 6.5 (3.5-11.4) and 6.6 (1.7-11.4) years, respectively. The most common complaints of the study group were urinary incontinence (58.8\%), encopresis (32.4\%) and constipation (17.6\%) and 41.2\% of patients needed diapers due to these problems. Twenty-five per cent $(n=5)$ of male patients had an undescended testis. The most common clinical conditions at urodynamics, were low bladder compliance (85.3\%), detrusor overactivity (67.6\%), hyposensitive bladder (52.6\%) and low bladder capacity $(41.2 \%)$.

Conclusion: Upper motor neuron lesions, like $\mathrm{CP}$, may present with various urodynamic findings. However, patients with $\mathrm{CP}$ are not routinely seen by urologists. Our findings revealed serious neurological problems in children referred for DRS. Therefore, every child with CP who has a DRS plan should undergo a detailed urological examination at least once before the procedure.
\end{abstract}

Keywords: Cerebral palsy, child, urology, urodynamics, rhizotomy

\section{Introduction}

Any damage to the developing brain can permanently lead to impaired control of movement and posture. These chronic palsies are broadly called "cerebral palsy" (CP) (1). This non-progressive brain disorder's spectrum of symptoms could change over time. It is the most common chronic disability in the childhood period (2). The underlying causes of $\mathrm{CP}$ are usually not known. However, predisposing factors, such as congenital abnormalities, genetic factors, infections, toxic factors, multiple gestations, vascular disease of pregnancy, preterm birth, postterm birth and maternal factors can lead to birth injuries and poor oxygen supply to the brain (3). The degree and location of brain damage finally shape the resulting motor and cognitive disabilities. CP has a broad spectrum of neurological findings that range from severe mental retardation and wheelchair-bound conditions to subtle

Correspondence:Tufan Tarcan MD, Marmara University Faculty of Medicine, Department of Urology, İstanbul, Turkiye Phone: +90 (216) 6570606 E-mail: tufan@marmara.edu.tr ORCID-ID: orcid.org/0000-0002-3387-3524

Received: 23.05 .20 Accepted: 22.09 .20

Cite this article as: Tanıdır Y, Özgen MB, Özek M, Tarcan T. Urodynamic Findings in Children with Cerebral Palsy Before Dorsal Rhizotomy Surgery. J Urol Surg 2021;8(1):33-39.

๑Copyright 2020 by the Association of Urological Surgery / Journal of Urological Surgery published by Galenos Publishing House. 
neurological impairments, which can only be detected on full neurological examination. Likewise, urological findings of these patients may also vary widely. Lower urinary tract dysfunction is estimated in one-third of CP patients (4). We evaluated the urodynamic and neurourological findings of children with $\mathrm{CP}$ who were scheduled for dorsal rhizotomy surgery (DRS) for neurological findings.

\section{Materials and Methods}

In this retrospective study, a consecutive group of children with CP who were referred and scheduled for selective DRS (SDR) to a tertiary centre, Marmara University Neurosurgery Department, Istanbul, between January 2005 and January 2008 was included as the study group. All patients were evaluated with a detailed history, physical examination, a neurourological work-up of urinalysis, renal function test (creatinine), ultrasonography and urodynamic studies. Inclusion and exclusion criteria for selective DRS are provided in a supplementary file.

\section{Criteria of Selective Dorsal Rhizotomy and Expected Outcomes}

Children diagnosed with spastic CP and referred to our institution and operated with SDR at the lumbosacral level were included in the study. The standardised measures used for the selection process consisted of the modified Ashworth scale to assess spasticity (defined as a velocity-dependent increase in the tonic stretch response), the Medical Research Council scale to measure muscle strength, goniometry assessments to indicate contractures the Gross Motor Function Classification System (GMFCS) for gross motor function and gait inefficiency according to non-dimensional oxygen cost. No standardised measurements were provided for the SDR selection criteria. The preoperative assessment was performed by a single person (neurosurgeon OM). However, the SDR selection preoperative assessment was also in consultation with a multidisciplinary team, consisting of neurosurgeons, orthopaedic surgeons, developmental paediatricians, paediatric neurologists, paediatric physiatrists, physical therapists, occupational therapists, nurses and/or social workers. The goals of SDR intervention were to improve motor function (walking ability, sitting and standing), prevent contractures and hip dislocation, and reduce pain.

\section{Inclusion Criteria for Selective Dorsal Rhizotomy}

\section{A. Body Structure and Function}

The presence of bilateral spasticity in the lower extremities [lower limbs (diplegia or tetraplegia)], which negatively influence gross motor function and/or caregiver support, were selected to be operated on with SDR. Patients with periventricular leukomalacia on neuroimaging were operated.

\section{B. Activity (Gross Motor Function)}

1. Patients should be able to walk with or without assistive devices.

2. GMFCS levels were used to define gross motor performance. Patients classified as GMFCS levels I to III were chosen for selective DRS operations.

\section{Personal and Environmental Factors}

1. Spastic CP was mentioned most commonly.

2. A history of preterm birth.

3. The origin of the spasticity should be in the context of a brain lesion acquired before one month of age.

4. Diagnoses other than spastic CP-like spasticity due to anoxia, encephalitis or degenerative diseases non-progressive spasticity due to hydrocephalus, spinal lesions or human immunodeficiency virus encephalomyelitis and spasticity of unknown origin with normal brain magnetic resonance imaging findings as well as hereditary spastic paraplegia.

5. The child's age at the SDR multidisciplinary consultation.

6. The child's and caregivers' motivation and access to follow-up therapy.

\section{Exclusion Criteria for Selective Dorsal Rhizotomy}

\section{A. Body Structure and Function}

1. The absence of movement abnormalities other than spasticity (such as ataxia, dystonia or choreoathetosis).

2. The absence of good antigravity strength.

3. The absence of good motor control.

4. The presence of contractures.

5. The presence of spinal abnormalities or severe scoliosis.

6. The presence of hip (sub)luxation.

7. The presence of cognitive impairment.

8. Neuroimaging criteria suggesting any abnormalities in the basal ganglia.

\section{B. Activity (Gross Motor Function)}

1. Patients should be able to walk with or without assistive devices.

2. Patients classified as GMFCS levels $>$ III.

\section{Personal and Environmental Factors}

1. As mentioned, a contraindication was previous orthopaedic surgery or treatment with botulinum toxin in the lower extremities within six months of SDR. 


\section{Urodynamic Evaluation}

Urodynamic investigations included flow rate, residual urine, filling and voiding cystometry, detrusor leak point pressure (DLPP) and external anal sphincter electromyography. A computerised urodynamic system, Solar Silver Urodynamic System (Medical Measurement Systems International, Dover, NH, USA), was used to evaluate the lower urinary tract. Urodynamic studies were conducted in all patients after urine sterilisation. In urinary tract infection cases, appropriate antibiotic treatment was started with the guidance of urine cultures. Urine cultures were repeated after treatment to ensure sterile urine at the time of urodynamic studies. All patients suffering from constipation received enemas before the urodynamic investigation.

Initially, a non-invasive uroflow study was conducted with external urethral sphincteric electromyographic recordings. All urodynamic tests were performed in the supine position with the induction of a transurethral of a $6-\mathrm{F}$ double lumen catheter and transrectal one-lumen catheter. Before the filling cystometry, residual urine volume was measured after the uroflowmetric. Later, the cystometric evaluation was started with a filling rate of $5 \mathrm{~mL} / \mathrm{min}$. Filling cystometry was limited to the sensation of a full bladder or total urine leakage. Total bladder capacity was taken as the total water volume infused until the end of filling the stage. All methods and definitions were based on the urodynamic standardisation of the International Continence Society (ICS) (5) and International Children's Continence Society (6). The expected bladder capacity is calculated using (age +1 ) $\times 30$ (5). The observations were made by direct visualisation, and bladder compliance was measured considering the pressure change starting from zero volume of infusion at the empty bladder, ending at the infusion value where the leakage occurred (7). Children with bladder compliance of $15 \mathrm{~mL} / \mathrm{cm}$ $\mathrm{H}_{2} \mathrm{O}$ and higher were assigned to the normal compliance group, whereas those with bladder compliance less than $15 \mathrm{~mL} / \mathrm{cm} \mathrm{H}_{2} \mathrm{O}$ were assigned to the low compliance group (8).

Namely, the ICS defines the DLPP as the lowest detrusor pressure value at which leakage occurs in the absence of abdominal pressure. The DLPP was measured by marking the lowest pressure when the urine seeped out from the urethral meatus. Continence was not assessed as a bothersome symptom under the age of three, as this is the age at which most children can postpone voiding and begin to achieve social daytime continence (9). In children younger than three years old and those with cognitive alterations, bladder sensation was not assessed. Constipation was considered as having fewer than three bowel movements per week (10).

Continuous data are given as median with the range in parentheses (the minimum and maximum values), and categorical data as the number of patients with the percentage of the total population in parentheses.

\section{Statistical Analysis}

Statistical analysis was done using International Business Machines (IBM) Statistical Package for Social Sciences (SPSS) Statistics for Windows (IBM Corp. Released 2017, Version 25.0. Armonk, NY: IBM Corp). The analysis was done as descriptive statistics. Shapiro-Wilk test was used to evaluate the distribution of variables and it was observed that the data did not show a normal distribution. Accordingly, continuous variables were expressed as median and minimum, maximum values and categorical variables as numbers and percentages.

\section{Results}

A total of 34 children [24 boys (70.6\%) and 10 girls (29.4\%)] were included in the present study. The mean age of boys, girls and the whole group at referral was 6.6 (1.7-9.8), 6.5 (3.5-11.4) and 6.6 (1.7-11.4) years, respectively. None of these children had prior urological evaluations or surgeries, and all were free of bladder medications. None of their parents was aware of a history of urinary tract infection. Serum creatinine levels were normal in all patients. A fifth of the male patients $(20.8 \%)(n=5)$ had an undescended testis (UDT) on physical examination (Table 1). There was no abnormal sacral cutaneous finding in any of the patients. The most common bothersome urological symptoms expressed by the study group were urinary incontinence (58.8\%), encopresis (32.4\%), constipation (17.6\%) and abnormal motor function of the lower extremity (91.3\%). Motor dysfunction, the problem in micturition control and

\begin{tabular}{|c|c|c|c|}
\hline & $\begin{array}{l}\text { Female } \\
(n=10) \\
N,(\%)\end{array}$ & $\begin{array}{l}\text { Male } \\
(n=24) \\
N,(\%)\end{array}$ & $\begin{array}{l}\text { Total } \\
(n=34) \\
N,(\%)\end{array}$ \\
\hline $\begin{array}{l}\text { Pathology on sacral } \\
\text { examination }\end{array}$ & $0(0 \%)$ & $0(0 \%)$ & $0(0 \%)$ \\
\hline Constipation & $3(30 \%)$ & $3(12.5 \%)$ & $6(17.6 \%)$ \\
\hline Encopresis & $1(10 \%)$ & $10(41.7 \%)$ & $11(32.4 \%)$ \\
\hline Daytime urinary incontinence & $2(20 \%)$ & $1(4.2 \%)$ & $3(8.8 \%)$ \\
\hline Nocturnal enuresis & 0 & $3(12.5 \%)$ & $3(8.8 \%)$ \\
\hline Day and night incontinence & $4(40 \%)$ & $10(41.7 \%)$ & $14(41.2 \%)$ \\
\hline $\begin{array}{l}\text { Normal function of lower } \\
\text { extremity }\end{array}$ & $1(10 \%)$ & $2(8.3 \%)$ & $3(8.8 \%)$ \\
\hline Wearing a diaper & $2(20 \%)$ & $12(50 \%)$ & $14(41.2 \%)$ \\
\hline $\begin{array}{l}\text { Patients without voiding } \\
\text { symptoms }\end{array}$ & $4(40 \%)$ & $10(41.7 \%)$ & $14(41.2 \%)$ \\
\hline $\begin{array}{l}\text { Patients with daytime } \\
\text { incontinence and encopresis }\end{array}$ & $1(10 \%)$ & $1(4.2 \%)$ & $2(5.9 \%)$ \\
\hline Being circumcised & NA & $8(33.3 \%)$ & NA \\
\hline Undescended testis & NA & $5(20.8 \%)$ & NA \\
\hline
\end{tabular}


encopresis were the predominant symptoms that forced $41.2 \%$ of the group to use diapers (Table 1). Of all patients, $3(8.8 \%)$ had only daytime, 3 (8.8\%) had only nighttime, and $14(41.2 \%)$ had diurnal incontinence episodes (Table 1). Renal ultrasonography did not reveal any abnormality, but mild hydronephrosis was present in the entire study group. None of the patients was previously on clean intermittent catheterisation (CIC). Some children had problems with co-operation during urodynamic studies, and because of this, inquiry about bladder sensation could not be performed and unfortunately, some could not void spontaneously. Therefore, 11 patients' (32.4\%) information about bladder sensation and 9 patients' (26.4\%) data about uroflowmetric studies are missing. All data about urodynamic studies are provided in Table 2. The most predominant urodynamic findings were low bladder compliance (85.3\%), detrusor overactivity (67.6\%), hyposensitive bladder (52.6\%) and low bladder capacity (41.2\%). Most children with CP seemed to have a normal bladder capacity (55.9\%) and poor bladder compliance $(85.3 \%)$ with urodynamic overactive detrusor (67.6\%). Although half of these patients seemed to have a hyposensitive bladder, only a few patients (12.5\%) with residual urine needed $\mathrm{ClC}$. However, the rest of the children with $\mathrm{CP}$ had mean flow rates that were quite slow. In our series, detrusor dyssynergia was not a common finding $(2.9 \%)$ in children with CP (Table 2).

\section{Discussion}

Previous studies had reported urological abnormalities and voiding dysfunction with urodynamic findings in $\mathrm{CP}$ patients. Patients with $\mathrm{CP}$ are an extremely heterogeneous group, ranging from simple impaired motor skills to requiring full-time nursing care with individualised therapy. Similarly, the location of lesions in the nervous system can change for all CP patients. Thus, only a few clinical studies reported various clinical findings and symptoms across the spectrum.

Lower urinary tract symptoms could be expected in about one- to two-thirds of CP patients (11). Urinary incontinence was reported to be the most common presenting symptom (47\%-74\%), followed by difficulty urinating $(44 \%)(11,12)$. Urge incontinence was reported to be the most common type of incontinence in children with CP (76\%) (11). Our patient population had a higher incidence of diurnal incontinence episodes. Concerning symptoms of micturition, only Bernuy and Lacert (13) reported dysuria as a common urological symptom in $\mathrm{CP}$, and none of our patients had a complaint like dysuria. As patients got older, difficulty in voiding became a more prominent symptom; however, urinary incontinence frequency did not change (14).

The most extensive epidemiological study of lower urinary tract symptoms in 459 children with CP was conducted by Roijen et al. (15). This heterogeneous group consisted of patients with low

Table 2. Urodynamic findings in children with CP

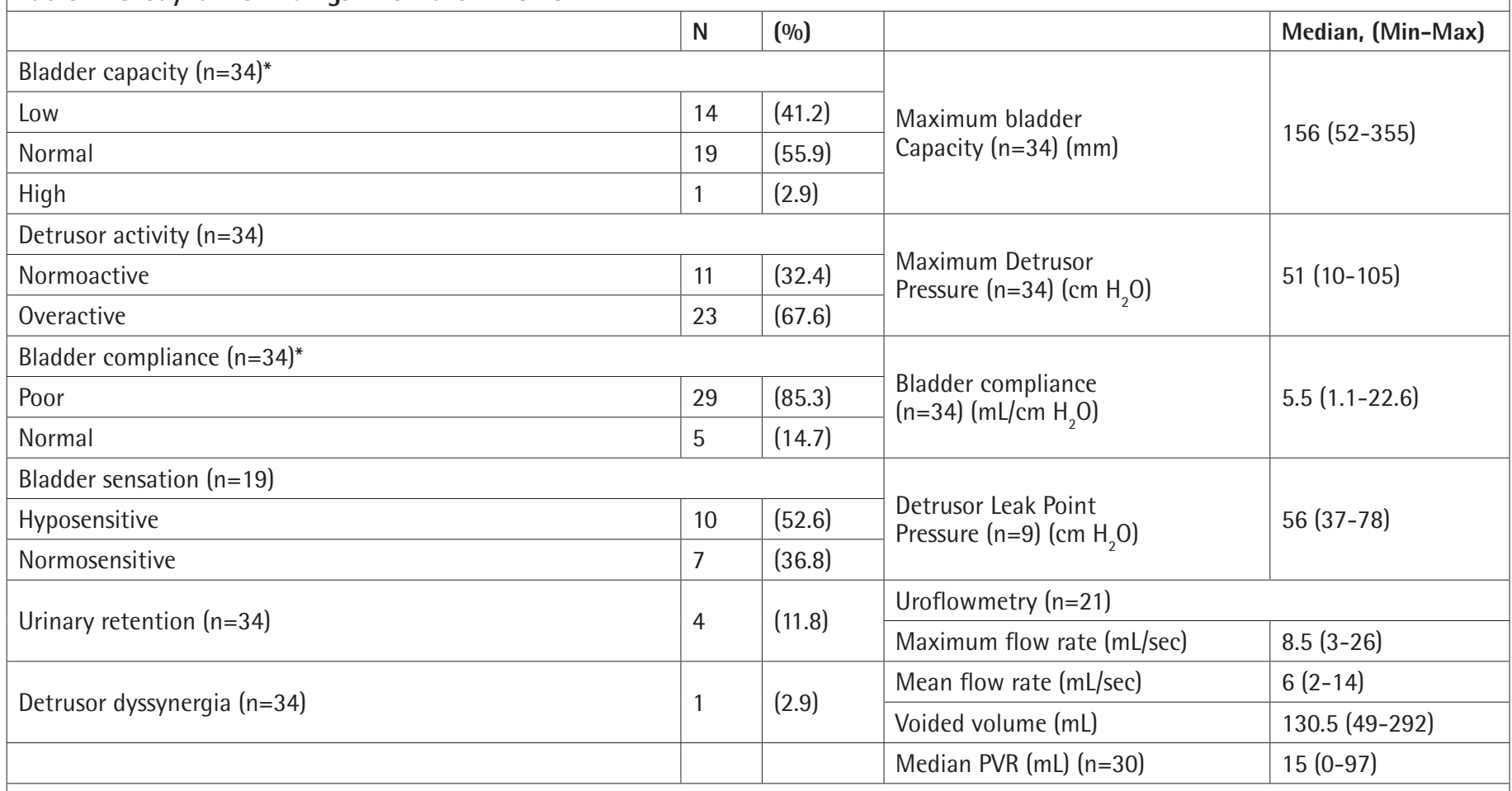

*Low bladder capacity = Less than 65 per cent of expected bladder capacity; high bladder capacity = More than 130 per cent of expected bladder capacity; poor bladder compliance is compliance less than $15 \mathrm{~mL} / \mathrm{cm} \mathrm{H}_{2} \mathrm{O}$; normal bladder compliance is compliance greater than $15 \mathrm{~mL} / \mathrm{cm} \mathrm{H}_{2} \mathrm{O}_{1}$ PVR: Post-void residual, CP: Cerebral palsy, Min: Minimum, Max: Maximum 
(30.1\%) and high (68.4\%) intellectual capacity, mainly spastic hemiplegia (30\%), diplegia (19.2\%) and spastic tetraplegia (46.2\%). The primary urinary incontinence prevalence of $23.5 \%$ (108 of 459) was reported for the whole study population, and all types of incontinence prevalence increased with age. The most important factors that influenced urinary incontinence in this group were tetraplegia and low intellectual capacity (15). Unfortunately, we cannot comment on our cohort's intellectual capacity as we did not assess it with a validated tool. We could not inquire about the information on bladder sensation because of co-operation problems (32.4\%). Children with mental retardation due to chromosomal aberrations, single-gene disorders, peri-/post-natal injuries and particularly those diagnosed with CP had a high UDT prevalence of (16). Confirming this, our patient group had a high incidence of UDT (20.8\%). A most probable mechanism for this high incidence is postulated by Smith et al. (17) with an increase in the cremaster muscle spasticity leading to the testis' pathologic retraction out of the scrotum.

Most studies inspected urological findings of CP patients when they were referred for urological problems, as did Decter et al. (18). They evaluated $57 \mathrm{CP}$ patients with urodynamic studies and reported pure upper motor neuron lesions and incomplete lower motor neuron injury in $86 \%$ and $11 \%$, respectively. The most common abnormalities detected in urodynamic studies were neurogenic detrusor overactivity (70\%), and detrusor sphincter dyssynergia (DSD) (12\%). Mayo studied urodynamics in $33 \mathrm{CP}$ patients with lower urinary tract symptoms. The main complaints of their patients were difficulty in voiding and urge incontinence. The least DSD percentage reported in the English literature was noted by Mayo (3\%) (19). Reid and Borzyskowski (12) studied urodynamics in $27 \mathrm{CP}$ patients and found abnormal findings in 85\%. The authors noted that hyper-reflexic detrusor contractions with reduced bladder capacity were the most common finding in 20 patients $(74.1 \%)$ and $18.5 \%(n=5)$ of all patients had DSD. Karaman et al. (11) studied urodynamics in 36 $\mathrm{CP}$ patients with lower urinary tract symptoms. They reported neurogenic detrusor overactivity with reduced bladder capacity as the most common finding (47.2\%), and DSD (11\%). Concerning the problems in bladder function, some authors elaborated on the urological care and assessment and suggested urodynamics for every child with infantile $\mathrm{CP}$, free of decision making, clinical findings and symptoms (20). This might be correct, since at least two-thirds of children with CP have clinically silent bladder dysfunction (21).

The present study suggested that one-third of the patients had normal bladder sensation, whereas $52.6 \%$ had a hyposensitive bladder. Neurogenic detrusor overactivity $(93.8 \%)$ with reduced bladder capacity (90.6\%) and low compliance (90.6\%) was cystometric evaluation's most common finding. As previously demonstrated by other studies, DSD was not a common feature for our population and only observed in one patient (2.9\%). Our patients' flow rate studies showed somewhat of a slow rate. Of all patients, $13(38.2 \%)$ could not void spontaneously, and 4 $(11.8 \%)$ got urinary retention following urodynamic assessment. The difficulty voiding might result from a hypertonic pelvic floor and a lack of voluntary control over the pelvic floor (19). However, it could also be due to a co-operation problem, which is not mentioned in any publications.

Mayo suggests that patients with urge incontinence seem to remain stable and respond to anticholinergics (19). This reason seems unlikely according to Reid and Borzyskowski (12). They explained that incontinence results from impaired mobility as there is a delay in reaching the toilet with a sudden urge to pass urine. Nevertheless, the mainstay of treatment in $\mathrm{CP}$ patients with dysfunctional voiding is anticholinergic drugs with or without $\mathrm{CIC}$. Almost all patients seemed to improve or get symptomatic relief (12). Since none of our patients had previously visited urology clinics before, they were not on any incontinence medications. However, almost $40 \%$ of them were wearing diapers for various problems. Another treatment option for these children is corrective surgery of the underlying pathology. Some studies reported improved spasticity and the bladder storage capacity following SDR $(21,22)$.

Any problem in bladder functions can lead to upper urinary tract deterioration. Gundogdu et al. (23) reported that $12.1 \%$ of upper urinary tract deterioration occurred in 33 children with CP. They concluded that other symptoms of bladder dysfunction and culture-proven true febrile urinary tract infection episodes were valuable indicators of upper urinary tract anomalies in children with CP. Unlikely, abnormal imaging findings were quite rare in our study. The utility of ultrasound was assessed by Silva et al. (24) to differentiate lower urinary tract dysfunction in patients with CP. However, bladder wall thickness did not correlate with the presence of bladder dysfunction in children with $\mathrm{CP}$.

Constipation is another issue in CP. Gundogdu et al. (23) reported that over half the children (57.5\%) had persistent constipation problems (fewer than three bowel movements in a week) for at least six months. Bladder dysfunction, elimination problems, constipation and decreased hygiene conditions cause bacteriuria or cystitis in $\mathrm{CP}$ children. So, it is also essential to ask about bowel problems. Mobilisation skills and nutritional status could contribute to bowel movements of children with CP. In healthy children, faecal load affects bladder functions, especially functional bladder capacity. Constipation may contribute to decreased bladder volumes in children with CP. The present study found that $17.6 \%$ of CP patients had constipation, and $32.4 \%$ had faecal soiling, affecting bladder functions. 
Children with $\mathrm{CP}$ are prone to urinary tract infections, and circumcision is advised in such cases. However, only 33.3\% of the children with $\mathrm{CP}$ were circumcised in our study group. This is unusual, as circumcision is also expected as a cultural element in Turkish society.

It is well known that patients with upper motor neuron lesions may present with different urodynamic findings. We cannot advise all CP patients to visit a urologist. However, the children who apply for SDR are a select group, which usually do not receive any prior evaluation and treatment by a urologist. Although these patients do not have upper urinary tract deterioration, they usually have pathologic bladder functions and need further treatment. A detailed urological evaluation should be suggested to every child. This assessment is important as lower urinary tract dysfunction, and UDT are common pathologies that require further treatment with anticholinergic therapy, $\mathrm{CIC}$, voiding and storage biofeedback, surgery, or follow-up before SDR.

Knowledge of urodynamic features and clinical problems in patients with $\mathrm{CP}$ is insufficient. Interestingly, there is limited data about neurourological findings of children with $\mathrm{CP}$, especially before DRS. At present, only 27 articles are published about urodynamic findings in children with $\mathrm{CP}$; however, only three of them address the findings in children before DRS $(21,22,25)$. The current study is providing the second-largest patient group about this topic.

\section{Study Limitations}

The present study is a non-randomised study with retrospective data analysis. No validated questionnaires were used to assess dysfunctional voiding patterns and constipation patterns. However, it is very challenging to complete these questionnaires in this patient population. Ultrasound was not utilised to measure bladder wall thickness. No urodynamic evaluation was present following DRS. Our patient group was a selected group limited to children with CP referred for DRS. Thus, two major limitations of the present study were the selection of cases and initial data collection. Another limitation is the utility of urodynamics studies without simultaneous videofluoroscopy. Patients with a neurogenic bladder can have secondary reflux. Therefore, the best practice is to perform videourodynamics to evaluate neurogenic patients. However, we lack this capability at our institution, and our patients did not have hydronephrosis in the ultrasonography. So, we did not ask for voiding cystourethrography study. A current study reported that the incidence of vesicoureteral reflux (VUR) in patients with CP was between $12.5 \%$ and $20 \%$. Also, the authors suggested that DSD was a risk factor as $89 \%$ of the children with CP and VUR had DSD (26).

\section{Conclusion}

Lower urinary tract dysfunction and abnormal physical findings on the urologic examination are not rare in children with $\mathrm{CP}$ referred for DRS. These patients should be assessed by a urologist before surgical intervention.

\section{Ethics}

Ethics Committee Approval: This study was approved by the local ethical committee of Marmara University School of Medicine (Application ID: 2021-168) and followed the Research Guidelines for the Institutional Review Board (IRB) of Human Subjects.

Informed Consent: Retrospective study.

Peer-review: Externally peer-reviewed.

\section{Authorship Contributions}

Surgical and Medical Practices: T.T., M.Ö., Concept: T.T., M.Ö., Y.T., M.B.Ö., Design: T.T., M.Ö., Y.T., M.B.Ö., Data Collection or Processing: Y.T., M.B.Ö., M.Ö., T.T., Analysis or Interpretation: Y.T., M.B.Ö., M.Ö., T.T., Literature Search: Y.T., M.B.Ö., M.Ö., T.T., Writing: Y.T., M.B.Ö., M.Ö., T.T.

Conflict of Interest: No conflict of interest was declared by the authors.

Financial Disclosure: The authors declared that this study received no financial support.

\section{References}

1. Rosenbaum $P$, Paneth $N$, Leviton $A$, Goldstein $M$, Bax $M$, Damiano D, Dan $B$, Jacobsson $B$. A report: the definition and classification of cerebral palsy April 2006. Dev Med Child Neurol Suppl 2007;109:8-14.

2. Himmelmann K. Epidemiology of cerebral palsy. Handb Clin Neurol 2013;111:163-167

3. Marret S, Vanhulle C, Laquerriere A. Pathophysiology of cerebral palsy. Handb Clin Neurol 2013;111:169-176.

4. McNeal DM, Hawtrey CE, Wolraich ML, Mapel JR. Symptomatic neurogenic bladder in a cerebral-palsied population. Dev Med Child Neurol 1983;25:612616.

5. Austin PF, Bauer SB, Bower W, Chase J, Franco I, Hoebeke P, Rittig S, Walle JV, von Gontard A, Wright A, Yang SS, Neveus T. The standardization of terminology of lower urinary tract function in children and adolescents: Update report from the standardization committee of the International Children's Continence Society. Neurourol Urodyn 2016;35:471-481.

6. Gammie A, Clarkson B, Constantinou C, Damaser M, Drinnan M, Geleijnse G, Griffiths D, Rosier P, Schäfer W, Van Mastrigt R; International Continence Society Urodynamic Equipment Working Group. International Continence Society guidelines on urodynamic equipment performance. Neurourol Urodyn 2014;33:370-379.

7. Tarcan T, Sekerci CA, Akbal C, Tinay I, Tanidir Y, Sahan A, Sahin B, Top T, Simsek F. Is $40 \mathrm{~cm} \mathrm{H} 2 \mathrm{O}$ detrusor leak point pressure cut-off reliable for upper urinary tract protection in children with myelodysplasia? Neurourol Urodyn 2017;36:759-763. 
8. Top T, Sekerci CA, Isbilen-Basok B, Tanidir Y, Tinay I, Isman FK, Akbal C, Simsek $F$, Tarcan $T$. The effect of intradetrusor botulinum neurotoxin type $A$ on urinary NGF, TGF BETA-1, TIMP-2 levels in children with neurogenic detrusor overactivity due to myelodysplasia. Neurourol Urodyn 2017;36:1896-1902.

9. Nijman R, Tekgul S, Janet C, Bael A, Austin PF, Von Gontard A. Committee 9: Diagnosis and management of urinary incontinence in childhood. In: Abrams P, Cardozo L, Khoury S, Wein A. Incontinence. Paris, ICUD-EAU, 2013, pp. 729-825.

10. Thompson WG, Longstreth GF, Drossman DA, Heaton KW, Irvine EJ, MullerLissner SA. Functional bowel disorders and functional abdominal pain. Gut 1999;45 Suppl 2(Suppl 2):I143-47.

11. Karaman MI, Kaya C, Caskurlu T, Guney S, Ergenekon E. Urodynamic findings in children with cerebral palsy. Int J Urol 2005;12:717-720.

12. Reid CJ, Borzyskowski M. Lower urinary tract dysfunction in cerebral palsy. Arch Dis Child 1993;68:739-742.

13. Bernuy $M$, Lacert P. Les troubles mictionnels chez les sujets porteurs de séquelles de lésions périnatales sans handicap intellectuel [Urination disorders in patients with sequelae of perinatal lesions without mental handicap]. Arch Pediatr 1997;4 Suppl 1:41s-43s.

14. Yokoyama 0 , Nagano $K$, Hirata A, Hisazumi H, Izumida S. [Clinical evaluation for voiding dysfunction in patients with cerebral-palsy]. Nihon Hinyokika Gakkai Zasshi 1989;80:591-595.

15. Roijen LE, Postema K, Limbeek VJ, Kuppevelt VH. Development of bladder control in children and adolescents with cerebral palsy. Dev Med Child Neurol 2001;43:103-107.

16. Cortada X, Kousseff BG. Cryptorchidism in mental retardation. J Urol 1984;131:674-676.

17. Smith JA, Hutson JM, Beasley SW, Reddihough DS. The relationship between cerebral palsy and cryptorchidism. J Pediatr Surg 1989;24:1303-1305.
18. Decter RM, Bauer SB, Khoshbin S, Dyro FM, Krarup C, Colodny AH, Retik $A B$. Urodynamic assessment of children with cerebral palsy. J Urol 1987;138:1110-1112.

19. Mayo ME. Lower urinary tract dysfunction in cerebral palsy. J Urol 1992;147:419-420.

20. Bross S, Pomer S, Döderlein L, Knoll T, Michel MS, Staehler G, Gerner HJ, Alken P. Videourodynamische Erstbefunde bei infantiler Zerebralparese [Urodynamic findings in patients with infantile cerebral palsy]. Aktuelle Urol 2004;35:54-57.

21. Houle AM, Vernet O, Jednak R, Pippi Salle JL, Farmer JP. Bladder function before and after selective dorsal rhizotomy in children with cerebral palsy. J Urol 1998;160:1088-1091.

22. Chiu PK, Yam KY, Lam TY, Cheng CH, Yu C, Li ML, Chu PS, Man CW. Does selective dorsal rhizotomy improve bladder function in children with cerebral palsy? Int Urol Nephrol 2014;46:1929-1933.

23. Gundogdu G, Komur M, Avlan D, Sari FB, Delibas A, Tasdelen B, Nayci A, Okuyaz C. Relationship of bladder dysfunction with upper urinary tract deterioration in cerebral palsy. J Pediatr Urol 2013;9:659-664.

24. Silva JA, Gonsalves Mde C, Saverio AP, Oliveira IC, Carrerette FB, Damiao R. Lower urinary tract dysfunction and ultrasound assessment of bladder wall thickness in children with cerebral palsy. Urology 2010;76:942-945.

25. Sweetser PM, Badell A, Schneider S, Badlani GH. Effects of sacral dorsal rhizotomy on bladder function in patients with spastic cerebral palsy. Neurourol Urodyn 1995;14:57-64.

26. Combs A, Van Batavia J, Glassberg K. Mp69-06 Vesicoureteral Reflux in Children With Cerebral Palsy: Incidence and Association With Detrusor Sphincter Dyssynergy. The Journal of Urology 2018;199(Suppl 4):e927. 